\title{
RESPONSABILIDADE CIVIL DO ESTADO POR OMISSÃO ESTATAL
}

\author{
Haide Maria Hupffer, Roberto Naime, Luiz Gonzaga Silva Adolfo \\ e Iose Luciane Machado Corrêa \\ CIVIL LIABILITY OF THE STATE FOR ENVIRONMENTAL NEGLECT
}

\section{RESUMO}

A Constituição Federal de 1988 É UM divisor dE ÁGUAS AO ASSUMIR-SE COMO CONSTITUIÇÃo AMBIENTAL, PROVOCANDO UMA RUPTURA EM RELAÇĀO AO CONCEITO DE RESPONSABILIDADE CIVIL. Partindo de uma abordagem qualitativa, dialética E JURISPRUDENCIAL, ESTE ARTIGO ANALISA O PRINCÍPIO RESPONSABILIDADE DESENVOLVIDO POR HANS JONAS E REALIZA UM DIÁLOGO COM O INSTITUTO DA RESPONSABILIDADE CIVIL AMBIENTAL, IDENTIFICANDO, COM APOIO NA LEGISLAÇÃO CONSTITUCIONAL E INFRACONSTITUCIONAL, AS CONTROVÉRSIAS DOUTRINÁRIAS ACERCA DA NATUREZA DA RESPONSABILIDADE ESTATAL (OBJETIVA OU SUBJETIVA) FRENTE A CASOS DE OMISSÃO DA ADMINISTRAÇÃO PÚBLICA E À OCORRÊNCIA DE DANO ambiental. Conclui-se que o Superior Tribunal de JUSTIÇA ASSUME UMA DIMENSÃO MAIS ALARGADA DO CONCEITO DE RESPONSABILIDADE CIVIL DO ESTADO, DEMONSTRANDO UMA TENDÊNCIA PELA RESPONSABILIDADE CIVIL OBJETIVA COM BASE NO RISCO. ASSIM, O BRASIL, SALVO ALGUMAS DIVERGÊNCIAS DOUTRINÁRIAS, ADOTA A RESPONSABILIDADE CIVIL OBJETIVA DO ESTADO PELA TEORIA DO RISCO ADMINISTRATIVO ALICERÇADA NO ATO ILÍCITO E NA ACEITAÇÃO DO RISCO.

\section{PALAVRAS-CHAVE}

Responsabilidade civil do Estado; Princíplo Responsabilidade; OMISSÃO AMBIENTAL; ASSENTAMENTOS URBANOS.

\section{ABSTRACT}

THE FEDERAL CONSTITUTION OF 1988 IS A 'WATER DIVISOR SINCE IT ASSUMES THE ROLE OF ENVIRONMENTAL CONSTITUTION, CAUSING A RAPTURE OF THE CONCEPT OF CIVIL LIABILITY. STARTING FROM A QUALITATIVE, DIALECTICAL AND JURISPRUDENTIAL APPROACH, THIS ARTICLE ANALYZES THE PRINCIPLE OF LIABILITY ACCORDING TO HANS JONAS IN ORDER TO DIALOGUE WITH THE INSTITUTE OF CIVIL ENVIRONMENTAL LIABILITY, IDENTIFYING, WITH THE SUPPORT OF THE CONSTITUTIONAL AND INFRACONSTITUTIONAL LEGISLATION, THE DOCTRINARY CONTROVERSIES ABOUT THE NATURE OF STATE LIABILITY (OBJECTIVE OR SUBJECTIVE) TOWARDS CASES OF NEGLECT BY THE PUBLIC ADMINISTRATION AND THE EVENT OF ENVIRONMENTAL DAMAGE. IT IS POSSIBLE TO CONCLUDE THAT THE HIGHER COURT OF JUSTICE ASSUMES A LARGER DIMENSION OF THE CIVIL LIABILITY OF THE STATE, THUS SHOWING THE TENDENCY TOWARDS THE OBJECTIVE CIVIL LIABILITY BASED ON THE RISK. THEREFORE, BRAZIL, REGARDED SOME DOCTRINARY DIFFERENCES, ADOPTS THE OBJECTIVE CIVIL LIABILITY FOR THE STATE THROUGH THE THEORY OF ADMINISTRATIVE RISK BASED ON THE ILLICIT ACT AND THE ACCEPTANCE OF THE RISK.

\section{KEYWORDS}

CIVIL LIABILITY; LIABILITY PRINCIPLE; ENVIRONMENTAL NEGLECT; URBAN SETTLEMENTS.

\section{INTRODUÇ̃̃O}

O instituto da responsabilidade civil é essencial à construção do Estado Democrático de Direito, na medida em que tem por finalidade precípua o restabelecimento do 
equilíbrio violado pelo dano. Por essa razão, prevê o nosso ordenamento jurídico a responsabilização civil não só por ato ilícito, mas também relativamente ao ressarcimento de prejuízos em que não se cogita da ilicitude da ação do agente ou até mesmo da ocorrência de ato ilícito. Isso se garante pela teoria do risco, tendo em vista a ideia de reparação ser mais ampla do que meramente o ato ilícito.

A responsabilidade do Estado obedece a um regime próprio, compatível com as suas atribuições e a potencialidade de danos que isso implica. Por isso, sua responsabilização civil é considerada, na maioria das vezes, pela teoria do risco administrativo, que conduz a pessoa jurídica de direito público à reparação do dano sofrido pelo particular por causa da administração independentemente da ocorrência de culpa, dolo ou de qualquer ilicitude (responsabilidade objetiva).

Já se encontra pacificada na doutrina a aplicabilidade da teoria da responsabilidade civil objetiva na responsabilização de condutas comissivas do ente público. Entretanto, quando se trata de omissão, apenas recentemente é que se encerrou mais um capítulo na história brasileira da evolução da responsabilidade civil do Estado, restando sedimentada a doutrina e a jurisprudência no sentido de serem aplicáveis tanto a responsabilização civil objetiva quanto a subjetiva, o que dependerá da análise caso a caso.

Sob esse contexto, analisa-se preponderantemente a responsabilidade civil do Estado na perspectiva do Princípio Responsabilidade desenvolvido por Hans Jonas para discutir a responsabilidade do Estado ante as ilicitudes da omissão estatal nas questões intergeracionais de preservação do meio ambiente. Hans Jonas escolheu o árduo e polêmico caminho de buscar uma ética para a civilização tecnológica que confere à ciência forças antes inimagináveis e à economia o impulso infatigável. O interesse de Hans Jonas consiste em fundamentar o Princípio Responsabilidade contra os abusos do poder do homem sobre a natureza. Há um modo próprio de mostrar que a ética ambiental tem a ver com o dever de conservar o mundo e preservar a vida no planeta. É por isso que se entende ser possível aproximar o Princípio Responsabilidade desenvolvido por Hans Jonas do maior desafio já imposto ao Estado: a responsabilidade civil do Estado em consequência da omissão deste na área ambiental. Não se trata tanto de apresentar sua teoria, mas de operarmos com seu Princípio Responsabilidade para clarearmos a responsabilidade do Estado em relação ao meio ambiente.

É com esse pano de fundo que será examinada a responsabilidade civil do Estado por omissão, com fundamento no $\S 6^{\circ}$ do artigo 37 da Constituição Federal. Já na sequência são abordadas as controvérsias doutrinárias e jurisprudenciais que envolvem o tema. Num primeiro momento, são expostos os elementos que integram as principais divergências entre doutrinadores acerca da natureza da responsabilidade estatal - ou seja, se esta é subjetiva ou objetiva - frente a casos de omissão da administração pública e à ocorrência de dano ambiental. São abordadas, ainda, recentes 
catástrofes ambientais, com o objetivo de instigar uma reflexão e introduzir a discussão sobre o fato de a sociedade de risco estar a exigir que o Estado não se omita no seu dever/poder de zelar pelo meio ambiente. Por fim, apresenta-se uma análise jurisprudencial do Superior Tribunal de Justiça (STJ), o qual tem se manifestado favorável à responsabilidade objetiva do Estado nos julgados analisados.

\section{i O Princípio Responsabilidade: UM diálogo COM Hans Jonas}

As recentes catástrofes ambientais, muitas delas resultantes de atos de omissão do poder público, colocaram diante da porta do Estado uma tarefa que nenhum governo tinha enfrentado com tal amplitude nas últimas décadas: o princípio da responsabilidade ambiental. Ou seja, o resultado inevitável de anos de omissão ou do excessivo uso do poder discricionário do Estado na concessão de licenças ambientais resultou inevitável: cada vez mais o Estado é chamado a se posicionar sobre o descumprimento de preceitos constitucionais e a responder civilmente por seus atos de ação ou omissão.

A situação-limite a que chegamos deve ser analisada à luz da teoria de Hans Jonas sobre o Princípio Responsabilidade. O autor parte da premissa de que o poder causal é pressuposto da responsabilidade e que, portanto, o agente público ou privado deve responder por seus atos e pelas consequências de suas ações. Para Jonas (2006, p.165), essa compreensão inicialmente deve se dar do ponto de vista legal, não moral. A responsabilidade "é a precondição da moral, mas não a própria moral”. Os danos causados "devem ser reparados, ainda que a causa não tenha sido um ato mau e suas consequências não tenham sido previstas, nem desejadas”. Esse dizer de Hans Jonas (2006, p. 165) está em consonância com o moderno entendimento do instituto da responsabilidade civil para questões ambientais, por sustentar que, para haver responsabilização, basta ter sido a causa ativa e que seja possível identificar um "nexo causal estreito com a ação, de maneira que a imputação seja evidente e suas consequências não se percam no imprevisível”.

De modo a evidenciar que o ser humano ao longo da história modificou sua forma de relacionar-se com a natureza, Hans Jonas (2006, p. 39) insere a expressão "vulnerabilidade da natureza" como o resultado da intervenção técnica do homem sobre o ambiente natural. Esse reconhecimento põe em xeque a civilização tecnológica, bem como a denúncia de que o ser humano colocou em perigo todas as formas de vida do planeta, inclusive a si mesmo. Sob tal ótica, a expressão "vulnerabilidade" assume um conceito mais alargado, ou seja, assim como o ser humano é vulnerável socioambientalmente frente aos fenômenos da natureza (naturais ou resultantes da ação humana), também a natureza passa a ser vulnerável em decorrência das práticas cumulativas de degradação ambiental que vem sofrendo pela intervenção tecnológica do ser humano. Essa abordagem de Jonas Hans traduz os ideais do geocentrismo 
ao reconhecer que a natureza está em situação de vulnerabilidade e perigo e que isso faz com que ela necessite de cuidados. Nessa perspectiva, o grande avanço está em compreender que a natureza da ação humana sobre o ecossistema foi modificada de fato ao longo da história. Assim como a de Sarlet e Fensterseifer (2011, p. 32), a teoria de Hans Jonas está pautada em uma visão que, ao conferir direitos à natureza, questiona a validade da concepção antropocêntrica de toda a ética moderna. Nesse contexto, Hans Jonas (2006, p. 39) alerta que "um objeto de ordem inteiramente novo, nada menos do que a biosfera inteira do planeta, acresceu-se àquilo pelo qual temos de ser responsáveis, pois sobre ela detemos poder”. Dito de outro modo, o homem passa a ter uma relação de responsabilidade com a natureza e com o futuro. Assim, a natureza como "responsabilidade humana é seguramente um novum sobre o qual uma nova teoria ética deve ser pensada” (Jonas, 2006, p. 39-40). E aí se questiona: Que tipo de deveres esse "dar-se conta" da vulnerabilidade da natureza exige dos Estados? É apenas a prudência para com as presentes e as futuras gerações?

Com o avanço da democracia e a consagração constitucional da proteção ambiental, cabe ao Estado e à coletividade serem guardiões da natureza e das futuras gerações, e os interesses desses dois grupos com grande frequência estão em conflitos: de um lado, as necessidades sociais e econômicas das presentes gerações exigem investimentos econômicos e, de outro lado, espera-se que as obrigações com as futuras gerações sejam cumpridas por meio da responsabilidade solidária. Esta deve ser compreendida como obrigações de prudência, apelando para a ideia de limite, visto que é o agir ilimitado do Estado e da coletividade que gera a fragilidade ambiental (Ost, 1997, p. 309-310).

A legislação constitucional brasileira assume esse dever de prudência e delega essa responsabilidade. Sua expressão máxima está no artigo 225 da Constituição Federal de 1988, no qual o legislador deixa aos cuidados do Estado o bem-estar, o interesse e o destino dos cidadãos. O artigo 225 deixa clara a responsabilidade do poder público em assegurar o direito ao meio ambiente ecologicamente equilibrado, bem de uso comum do povo e essencial à sadia qualidade de vida. Esse artigo consolida a opção do Brasil de ser uma democracia socioambiental.

Por outro lado, é nesse aspecto - dever/poder do Estado - que reside o grande dilema da pós-modernidade. Recorrendo novamente a Hans Jonas, percebe-se que o autor enfrenta a responsabilidade do Estado na seguinte afirmativa: "o exercício do poder sem a observação do dever é, então, 'irresponsável'”. A reflexão de Jonas é no sentido de que o não cumprimento, pelo Estado, de seu dever de assegurar a permanência de uma autêntica vida humana sobre a terra "representa uma quebra da relação de confiança presente na responsabilidade” (Jonas, 2006, p. 168).

Seguindo na mesma reflexão, diferentemente do imperativo categórico do Kant, Jonas, sob um viés da biologia filosófica, traz um novo imperativo, que é o centro de sua ética da responsabilidade, voltado para um novo tipo de sujeito mais atuante na 
sociedade. Esse imperativo, para Jonas (2006, p. 47), deveria ser: "Aja de modo que os efeitos de tua ação não sejam destrutivos para a possibilidade futura de uma autêntica vida humana sobre a terra”.

O imperativo formulado por Jonas pode ser compreendido no contexto das omissões do Estado em questões ambientais e das consequências de tais ações, ou seja, dos acontecimentos que o Estado poderia ter evitado - em casos de degradação ou desastres ambientais - intervindo pelo princípio da prevenção e pelo princípio da precaução. Ele se diferencia de Kant (voltado ao indivíduo) ao aplicar seu imperativo à política pública. Sua proposta de imperativo clama por outra coerência: não do cidadão consigo mesmo, mas dos efeitos finais da ação ou omissão na perspectiva da política pública para a continuidade da atividade humana no futuro.

E o mais importante: seu imperativo se "estende em direção a um previsível futuro concreto," que para Jonas (2006, p. 48) constitui a "dimensão inacabada de nossa responsabilidade”. Dessa maneira, com base nas formulações éticas trazidas ao texto, é possível inferir que o Estado não tem o direito de arriscar a vida da humanidade nem de escolher a não existência de futuras gerações ou mesmo de as colocar em risco.

Por fim, pontua-se que, pelo artigo 225 da Constituição Federal (CF/88), o Estado tem o dever de assegurar o direito ao meio ambiente ecologicamente equilibrado, bem de uso comum do povo e essencial à sadia qualidade de vida. Por isso, o tema da responsabilidade é sempre atual, principalmente a responsabilidade civil ambiental do Estado por omissão, visto que seu compromisso é com a proteção ambiental para as presentes e as futuras gerações.

Esse diálogo com Jonas possibilita resgatar na ética elementos para justificar a tutela jurídico-constitucional do meio ambiente e a responsabilidade do Estado, em especial quando este infringir os preceitos do Estado Socioambiental Constitucional por conduta omissiva perante o bem ambiental. Na sequência, o objetivo é transcender o Princípio Responsabilidade de Jonas para o discurso jurídico, sinalizando pela legislação constitucional e infraconstitucional a concretude do Princípio da Responsabilidade Civil do Estado por Omissão.

\section{A Responsabilidade Civil do Estado por Omissão}

A regra geral da responsabilidade civil do Estado está esculpida no $\S 6^{\circ}$ do artigo 37 da Constituição Federal, o qual determina que as pessoas jurídicas de direito público respondam objetivamente pelos danos que os seus agentes, nessa qualidade, causarem a terceiros. Para configurar a responsabilidade civil do Estado é necessário que se demonstre o nexo de causalidade entre os danos causados e a conduta tanto das pessoas jurídicas de direito público quanto das de direito privado prestadoras de serviço público, sendo desnecessária a prova de culpa - ou seja, o ato não precisa ser ilícito, basta a comprovação do dano e o nexo causal entre a atividade estatal e o resultado danoso. 
No entanto, por muito tempo perdurou a noção de que, quando o dano foi possível em decorrência de uma omissão do Estado, a responsabilização civil do ente público deveria ser analisada impreterivelmente sob o manto subjetivo, com base nas normas infraconstitucionais que regulam esse tema, sendo necessária, nessa hipótese, a comprovação inequívoca de ato ilícito praticado de forma ativa ou passiva, além da efetividade do dano e o nexo de causalidade deste em relação a determinada conduta, também a ocorrência de culpa lato sensu. Assim, na responsabilidade civil subjetiva o debate principal se dá em relação à culpa.

O ordenamento jurídico ambiental, pela complexidade dos bens tutelados, rompe com a noção tradicional de responsabilidade civil, exigindo a lógica da imputação objetiva, visto que o bem tutelado é direito coletivo e de difícil recuperação ou reparação. A Lei n 6. 938/81, que instituiu a Política Nacional do Meio Ambiente, põe em relevo o princípio da responsabilidade objetiva em seu art. $14, \S 1^{\circ}$, fundamentado sua adoção pela teoria do risco da atividade. A Constituição Federal de 1988 recepciona esse dispositivo no artigo 225, § 3º , ao estabelecer: "As condutas e atividades lesivas ao meio ambiente sujeitarão os infratores, pessoas físicas ou jurídicas, a sanções penais e administrativas, independentemente da obrigação de reparar os danos causados". Outro dispositivo infraconstitucional importante é o artigo 187 da Lei $n^{\circ} 10.406 / 2002$.

A aplicabilidade da responsabilização civil por dano ao meio ambiente, nas palavras de Carvalho (2008, p. 112), depende "de comprovação da existência de um dano, de uma conduta e de uma relação de causa e conseqüência entre estes”. O problema prioritário dessa responsabilidade recai sobre a existência ou não do nexo de causalidade, "quer na determinação da extensão da participação de determinado agente, quer na própria existência ou não de uma relação de causa e efeito”.

Assim, no sistema jurídico ambiental brasileiro, a responsabilidade civil objetiva é regra geral e se fundamenta na teoria do risco, não sendo necessário comprovar a culpa do agente "para que seja obrigado a reparar o dano causado. Basta que ele assuma o risco de prejudicar o meio ambiente" (Leite, 2006, p. 47). Portanto, é irrelevante definir se o dano ambiental resulta de uma conduta culpável sempre que se estiver diante de qualquer atividade que, direta ou indiretamente, ocasione degradação ao meio ambiente.

A revitalização do instituto da responsabilidade civil ambiental e sua fundamentalidade formal encontram-se ligadas ao Estado Socioambiental de Direito, resultando que o Estado responde tanto por ato omissivo - quando deixa de fazer o que tinha que fazer - quanto por comissão - quando faz o que não deveria fazer. Além do exposto, o Estado pode ser responsabilizado civilmente "até mesmo, solidariamente, por danos causados por terceiros, pois cabe ao Estado defender e preservar o meio ambiente, podendo o ente político exercer o seu direito de regresso em relação ao agente causador direto do prejuízo" (Jucovsky, 2000, p. 55). 
A Constituição Federal de 1988 é um divisor de águas ao assumir-se como Constituição Ambiental. O poder público - entendido como União, Estados da Federação, Distrito Federal, municípios e todos os entes políticos -, por força do inciso VI do artigo 23 da CF, tem o dever de proteger o meio ambiente e fiscalizar sua conservação, combater a poluição em qualquer de suas formas, manter os ecossistemas, promover o uso sustentável dos recursos naturais e adotar medidas preventivas e compensatórias.

A omissão também é causa de dano ambiental e traz no seu contexto o "frustrado princípio ativo do dever estatal não cumprido” (Freitas, 2005, p. 159) ao deixar de agir preventivamente em questões ambientais. Com isso, descumprem-se os preceitos constitucionais e infraconstitucionais de zelar por um meio ambiente equilibrado na perspectiva da solidariedade intergeracional.

Milaré (2009) destaca que o ente público não se expõe como agente poluidor ao controle do Poder Judiciário apenas quando causa dano ao meio ambiente por atividade que executa - como nos casos de construção de estradas, aterros sanitários, troncos coletores e emissários de esgotos sanitários sem realização de estudo de impacto ambiental. Para o autor, o ente público também é responsabilizado "quando se omite no dever constitucional de proteger o meio ambiente (falta de fiscalização, inobservância das regras informadoras do processo de licenciamento, inércia quanto à instalação de sistemas de disposição de lixo e tratamento de esgotos, por exemplo)" (Milaré, 2009, p. 909). Além de violar um dever jurídico, o Estado, pela sua omissão, contribui para a exacerbação de riscos ambientais.

Em se tratando de dano ao meio ambiente, percebe-se uma ruptura em relação ao tradicional conceito de responsabilidade civil. Ou seja, identificada a conduta omissiva estatal, esta é suficiente para determinar a responsabilidade objetiva do Estado por sua reparação. Assim, "no simples conceito de descumprimento de obrigação exigível já está embutida a ideia de culpa, só elidível se não demonstrada a excludente de inexigibilidade do ato omitido, posto como causa do dano" (Cahali, 1995, p. 286).

Nesse ponto é possível uma aproximação com o pensamento de Jonas quando esse autor aborda a omissão do Estado ante certos experimentos tecnológicos (como é o caso dos alimentos transgênicos e das nanotecnologias). Para Jonas, a existência ou a essência do homem, em sua totalidade, nunca pode ser transformada em aposta do agir.

O Estado, ao se omitir, assume a responsabilidade pelas consequências dos riscos que podem acometer o ser humano e o meio ambiente. Isso, para Jonas, não é um mero conselho de prudência moral, mas um mandamento irrecusável, "na medida em que assumimos a responsabilidade pelo que virá” (Jonas, 2006, p. 77-173). Pelo princípio da responsabilidade, o Estado assume a responsabilidade plena pela vida da comunidade, o que Jonas chama de "bem público". Assim, o Estado não tem o direito de arriscar o interesse da coletividade no jogo da incerteza pela omissão. 
Para alguns doutrinadores, entre os quais se destaca Celso Antônio Bandeira de Mello (1981), não há unanimidade quanto à responsabilidade objetiva ou subjetiva. $\mathrm{Na}$ visão de Mello, é possível o Estado responder objetivamente sempre que os danos ensejadores da reparação tenham sido causados por agentes públicos. No caso de os danos não serem causados por tais agentes, "se incorreram em omissão e adveio dano para terceiros, a causa é outra; não decorre do comportamento dos agentes. Terá sido propiciada por eles. A omissão haverá condicionado sua ocorrência, mas não a causou” (MELLO, 1981, p. 13). Ainda, para o autor, não há como cogitar responsabilidade objetiva nesse caso. Dito de outro modo, a responsabilidade por omissão é responsabilidade por comportamento ilícito. É nesse ponto que Mello (1981, p. 13) discorda da maioria dos doutrinadores ambientalistas: ele considera que, nesse caso, a responsabilidade é subjetiva, visto que "supõe dolo ou culpa em suas modalidades de negligência, imperícia ou imprudência, embora possa tratar-se de uma culpa não individualizável na pessoa de tal ou qual funcionário, mas atribuída ao serviço estatal genericamente”. Para fundamentar sua hipótese, referencia que se trata de "culpa anônima ou 'faute de service' dos franceses, entre nós traduzida por 'falta do serviço'” (Mello, 1981, p. 13).

Para compreender os diferentes tipos de omissão, Sérgio Cavalieri Filho nos dá um belo exemplo, do qual se extrai o seguinte trecho:

Se um motorista embriagado atropela e mata pedestre que estava na beira da estrada, a Administração (entidade de trânsito) não poderá ser responsabilizada pelo fato de estar esse motorista ao volante sem condições. Isso seria responsabilizar a Administração por omissão genérica. Mas se esse motorista, momentos antes, passou por uma patrulha rodoviária, teve o veículo parado, mas os policiais, por alguma razão, deixaram-no prosseguir viagem, aí haverá omissão específica que se erige em causa adequada do nãoimpedimento do resultado. Nesse segundo caso haverá responsabilidade objetiva do Estado (Cavalieri Filho, 2007, p. 231).

Note-se que em ambas as hipóteses de responsabilização por omissão se trata de responsabilidade extracontratual, cujo fator determinante para estabelecer se a responsabilidade é objetiva ou subjetiva reside na existência ou não do dever individualizado de agir, o que igualmente determinará o tipo de omissão perpetrada.

A estrutura dogmática da responsabilidade civil por danos ambientais tem seu fundamento na teoria do risco concreto e exige, para sua comprovação, um dano concreto ao meio ambiente. A sociedade pós-industrial traz um novo tema para discussão, que é o risco abstrato decorrente da proliferação de riscos imprevisíveis e globais (Carvalho, 2008, p. 74-77). Essa discussão deve fazer parte das preocupações do Estado, visto que, pelo artigo 225 da CF, ele tem o dever de se preocupar com atos de omissão ante as incertezas científicas geradas pelo processo de 
industrialização tecnológica da sociedade pós-moderna e com seus reflexos para as presentes e futuras gerações.

À luz de tais ponderações, os mais recentes julgados admitem a ideia de que há dois tipos de omissão estatal, quais sejam: a omissão geral ou genérica e a omissão específica, que ocorrem quando determinado serviço não funciona ou funciona deficitariamente, respectivamente.

\section{I OMISSÃO ESPECÍ́FICA}

A omissão específica se verifica nas hipóteses em que o evento danoso decorreu diretamente da inação do ente público, figurando a inércia administrativa como causa direta e imediata da ocorrência do resultado danoso. Nesse caso, sua omissão cria "a situação propícia para a ocorrência do evento em situação em que tinha o dever de agir para impedi-lo" (Cavalieri Filho, 2007, p. 261) e não o fez, hipótese em que a sua responsabilização civil extracontratual será objetiva, fundada na teoria do risco administrativo, consoante os artigos $37, \S 6^{\circ}$, da Constituição Federal e 43 do Código Civil.

Para Freitas (2005, p. 146), o Estado brasileiro "precisa deixar de ser omisso na concretização da eficácia direta e imediata dos direitos fundamentais”. O meio ambiente é um direito fundamental. O Estado tem o dever constitucional de evitar os acidentes ambientais ou de ao menos reduzir o número e a gravidade destes. A função essencial do instituto da responsabilidade civil por dano ambiental seria, no caso de omissão específica, evitar que a repulsiva inoperabilidade do Estado frente ao dever constitucional de preservar o meio ambiente causasse dano injusto à coletividade. Em nome do interesse público marcante do princípio da solidariedade intergeracional, o Estado tem que ser acordado para a realidade gritante da omissão de seus entes.

Aqui é possível encontrar aderência ao pensamento de Jonas. Para Jonas, a assistência governamental "não pode tirar férias", pois a vida da coletividade segue em frente, renovando as demandas ininterruptamente. Há uma dignidade humana a ser garantida para as gerações presentes e futuras, que está sob a responsabilidade do Estado. A inclusão do amanhã nas ações ou nas omissões do Estado capazes de gerar risco concreto ou abstrato tem a ver com temporalidade e ganha uma dimensão totalmente diferente em relação à responsabilidade do Estado. Dito de outro modo, com o surgimento da sociedade de risco, o marco temporal da responsabilidade do Estado "comporta um conteúdo inteiramente novo e um alcance nunca visto sobre o futuro, na esfera do fazer político” (Jonas, 2006, p. 77-173). Assim, o deixar de executar uma atividade ou de prestar algum serviço público está em desacordo com as novas responsabilidades do Estado, visto que, além de para com as presentes gerações, o Estado tem um dever para com as futuras gerações (art. 225 da CF/88) e a omissão pode significar perda de qualidade de vida.

Os riscos, na concepção de Ulrich Beck (2008, p. 157 e 224), se baseiam sempre 
em decisões, ou seja, esse autor pressupõe que há a possibilidade de decidir. Para ele, a sociedade de risco global é fruto da inércia do Estado diante de séculos de racionalidade econômica sem a devida autocrítica a respeito dos riscos e dos perigos que as decisões ou as omissões estatais poderiam gerar ao meio ambiente. Beck chama a atenção para o fato de que o Estado se dirige, na maioria dos casos, apenas aos problemas cotidianos decorrentes de dano ao meio ambiente que são visíveis, o que pressupõe que há um déficit de responsabilização e imputação, bem como uma racionalidade limitada aos riscos concretos da sociedade industrial.

Os riscos e os perigos ecológicos são extremamente complexos e marcados por sua globalidade, transtemporalidade e invisibilidade. Por isso a necessidade de revitalizar o instituto da responsabilidade civil para que o Estado exerça a sua função constitucional de preservar o meio ambiente.

Outro ponto que merece atenção e que está relacionado à responsabilização objetiva é a diretiva de inverter-se o ônus probatório em desfavor do Estado, o qual somente poderá elidir a responsabilidade mediante a comprovação da ocorrência de alguma das excludentes.

\subsection{OMISSÃO GENÉRICA}

Já a omissão genérica se verifica quando a ocorrência do dano não se dá diretamente em razão da inércia do Estado, mas sim em decorrência de falta do serviço, ou faute du service, seja porque este não funcionou quando deveria normalmente funcionar, seja porque funcionou mal ou tardiamente, hipóteses em que é dispensável a prova de que qualquer agente do Estado tenha incorrido em culpa, já que esta se dilui na sua própria organização.

Nesse ponto a doutrina e a jurisprudência divergem. Para doutrinadores, entre os quais se destacam Mello, Vitta e Alexandrino, sempre que diante de tais hipóteses, deve ser aplicada a teoria da responsabilidade subjetiva - o que exige, portanto, a comprovação, por parte da vítima, da ocorrência de culpa lato sensu: dolo, negligência, imperícia ou imprudência do Estado, no sentido de que o serviço que lhe incumbia prestar falhou de alguma forma.

Vitta (2008, p. 87-9) observa que, quando se fala em responsabilidade civil do Estado, fala-se em comportamento do agente público, pois é por intermédio deste que o Estado pratica suas ações. Esse agir pode ser comissivo ou omissivo. Sempre que se tratar de ato omissivo específico, deve-se ter presente que ele pode ser lícito ou ilícito, e a responsabilidade será baseada no critério objetivo. Por outro lado, o autor adota a responsabilidade civil estatal subjetiva quando se está diante de omissão genérica - ou seja, quando a Administração não age na defesa do meio ambiente, ao adotar conduta omissiva por inércia ou abstenção (faute du service) e desta resultar lesão ao meio ambiente -, baseando seu entendimento no conceito de falta de serviço, ou seja, negligência, imprudência ou imperícia. 
Para configurar responsabilidade civil subjetiva, a conduta do Estado seria, acaso existisse, apta a impedir o surgimento da circunstância causadora do dano (Vitta, 2008, p. 90). Aqui é desnecessário individualizar os elementos da culpa instaurada, pois estes podem ser atribuídos, de forma genérica, à falta do serviço faute du service -, sendo anônima relativamente aos agentes.

Mello afirma também que, se o dano decorre de uma omissão do Estado (o serviço não funcionou, ou funcionou tardia ou ineficientemente), deve-se aplicar a teoria da responsabilidade subjetiva. O autor justifica sua posição argumentando que o Estado, ao não agir, não pode ser o autor do dano e, assim, "só cabe responsabilizá-lo caso esteja obrigado a impedir o dano. Isto é: só faz sentido responsabilizá-lo se descumpriu dever legal que lhe impunha obstar ao evento lesivo" (Mello, 1992, p. 346).

Sustentando a responsabilidade civil do Estado por omissão genérica como responsabilidade subjetiva, Alexandrino e Paulo (2004, p. 410) trazem um exemplo de ocorrência de danos ambientais e de sérios prejuízos à população em função de fenômenos da natureza, como vendavais, chuvas e enchentes. Para o autor, nessas hipóteses, a "indenização estatal só será devida se restar comprovada a culpa da Administração [responsabilidade subjetiva]”.

$\mathrm{Na}$ linha aberta por alguns doutrinadores, percebe-se nas recentes decisões judiciais o posicionamento pela responsabilidade civil objetiva também para casos de omissão genérica. Sua base de sustentação está na necessidade de estabelecer um sistema de responsabilização estatal por dano ao meio ambiente acompanhando o moderno conceito de responsabilidade civil ambiental fundamentado no risco.

Claro que é necessário admitir algumas excludentes de responsabilidade. Baracho Júnior (2000, p. 322-323) inicia esse diálogo colocando que o "instituto da responsabilidade civil por dano ao meio ambiente não pode pretender absorver o mundo da vida, dinâmico e sempre mais rico do que o mundo do discurso por definição" (grifou-se). Para o autor, o problema não se "resume à definição clara de quem deve responder pelo dano ao meio ambiente, mas porque deve responder".

Essa provocação levantada por Baracho Júnior pode ser assim respondida, voltando à questão da responsabilidade civil por omissão genérica: se o Estado deixar de implementar conduta considerada indispensável e sobrevier fenômeno natural que cause danos diretamente pela falta da referida conduta, essa omissão do poder público ensejará a responsabilização deste, visto que estará presente o nexo de causalidade entre o ato omissivo e o dano, já que a causa imediata do dano não é o fato de força maior, mas o desleixo do Estado em, sendo possível prever tal fenômeno e suas consequências, nada fazer para evitá-las.

Assim, a posição assumida no presente estudo é contrária aos argumentos em favor da responsabilidade civil subjetiva. Sustenta-se que, embora os fatores climáticos figurem, via de regra, como excludentes de responsabilização, nos casos de força 
maior, ainda assim há hipóteses em que se pode responsabilizar civilmente o Estado pelos danos decorrentes de fenômenos da natureza.

Por outro lado, há de se ter cuidado em acionar indiscriminadamente o Estado na condição de "poluidor indireto" pelos danos ambientais causados por terceiros quando ele se omitiu de fiscalizar determinado empreendimento ou não impediu a ocorrência do dano ambiental. O Estado não pode se converter em um "segurador universal” (Freitas, 2005, p. 160). Vale dizer que isso significaria transferir:

... à própria vítima última da degradação - a sociedade - a responsabilidade pela reparação do prejuízo, com todos os ônus daí decorrentes, quando, na verdade, a regra deve ser a da individualização do verdadeiro e principal responsável, evitando-se, com isso, indesejável socialização dos encargos necessários à reparação de danos ambientais praticados por particulares - pessoas físicas e jurídicas - que podem ser determinados (Mirra, 2010, p. 7).

Com isso não se está a dizer que o Estado não deve ser responsabilizado solidariamente por omissão quando o autor do dano é um particular (pessoas físicas ou jurídicas). O que se questiona é se o Estado deve ou não responder solidariamente. Nesse sentido, acompanhamos Heli Alvez Oliveira, que, na perspectiva de Mirra (2010, p. 7), tem sustentado que "somente em caso de culpa grave, ou seja, de omissão injustificável das autoridades, é que deveria admitir a responsabilização solidária do Estado pelos danos ambientais praticados por terceiros”.

No Brasil, apesar de uma Constituição que se conclama socioambiental e da vasta legislação que delega ao Estado a proteção ao meio ambiente, pode-se dizer que ainda se está longe de internalizar os princípios constitucionais e as leis infraconstitucionais e de transformá-los em realizações de fato do Estado.

$\mathrm{Na}$ sequência, serão objeto de análise algumas condutas omissivas do Estado que podem, sim, ensejar responsabilidade civil objetiva do Estado, embasando, assim, a posição assumida.

\section{Condutas omissivas e a negligência em relação AOS ASSENTAMENTOS URBANOS}

Infelizmente, um claro exemplo disso é a tragédia que assolou Angra dos Reis no Estado do Rio de Janeiro no dia $1^{\text {a }}$ do ano de 2010 e, novamente, no início do ano de 2011 em outra região do mesmo Estado. Não fosse omisso o poder público municipal relativamente à correta fiscalização das obras e das construções nos morros e nas suas encostas - realizando, inclusive, estudos de solo adequados -, evidentemente não teriam os danos provocados pelas chuvas adotado proporções catastróficas. 
$\mathrm{Na}$ verdade deve se reconhecer que esse é um problema quase planetário. Não existem políticas públicas eficazes e eficientes de usos e ocupação dos solos ou dos espaços territoriais em praticamente nenhum local do mundo. Grandes cidades, como São Francisco e Los Angeles, estão em áreas tectonicamente muito vulneráveis, praticamente sobre uma estrutura geológica denominada Falha de Santo André, ou San Andreas Fault. Esse tipo de crosta ocorre como reação aos movimentos de acomodação das placas tectônicas continentais que sempre ocorreram. A terra tem sua geodinâmica, e os processos que acompanham estas alterações são bem conhecidos. Sempre ocorrerão manifestações de vulcões e terremotos nas zonas de subducção, ou seja, onde um continente de composição ferromagnesiano mais pesado submerge embaixo de outro com composição alumino silicosa mais leve. É o que ocorre em toda a margem andina, na América Central, e em toda a costa oeste dos Estados Unidos.

De acordo com Rohde (1990, p. 273), sempre que processos geodinâmicos entram em conflito com a ação humana há uma grande probabilidade de ocorrer “'perigos' ou 'catástrofes' ecológicas”. Rohde prefere chamar esses processos/acontecimentos de "risco". Em sua argumentação, sustenta que o risco advém do fato de que grande parte das catástrofes ecológicas poderiam ter sido resolvidas (total ou parcialmente) ou evitadas com o uso da inteligência humana se a elas fosse dada a devida atenção (Rohde, 1990, p. 273). Em sentido similar, Metzger (1996) posiciona que os acidentes ambientais revelam e materializam o risco. Essas reflexões permitem dizer que hoje é consensualmente aceito que os fenômenos geológicos integram o contexto das manifestações ambientais. Nesse sentido, a responsabilidade do Estado sobre o assentamento de populações nessas áreas com alto potencial de risco poderia ser questionado, ao menos modernamente.

Por outro lado, importa registrar que o assentamento de populações em encostas sujeitas à instabilização de terras com ou sem chuvas e em áreas inundáveis são os conceitos de áreas de risco mais desenvolvidos na engenharia, e não se discute a obrigação do Estado de prevenir o assentamento de populações em áreas de risco. Convém lembrar que cabe ao Estado produzir mapas geotécnicos e, com base nesses documentos, fiscalizar o assentamento de populações nesse tipo de área, porque, se essa decisão for deixada ao livre-arbítrio das forças de mercado, as populações de mais baixa renda e mais excluídas socialmente e economicamente sempre serão induzidas à ocupação de áreas de risco, sejam elas de instabilização de taludes, sejam inundáveis.

Apenas para ilustrar, Bohn, Silva e Bevian (2009) denunciam que no ano de 2008, na região do Vale do Itajaí, Estado de Santa Catarina, ocorreu uma instabilização (escorregamento) de grandes proporções no morro do Coripós (Blumenau). Na análise dos autores, esse era um desastre anunciado. Desde 1983, inúmeros estudos e documentos enviados e protocolados na prefeitura de Blumenau demonstravam, 
com apoio de pesquisas geológicas, a instabilidade do solo e as inúmeras fraturas existentes no terreno com risco iminente de desmoronamento, bem como indicavam a necessidade urgente da completa evacuação da área. Dez dias antes do desastre, os técnicos enviaram novamente um memorando para a Defesa Civil ratificando a existência do risco. O resultado da omissão do poder público se refletiu no dia 20 de novembro de 2008, quando o morro Coripós deslizou sobre inúmeras casas arrastando grande quantidade de terra, árvores inteiras, lixo, esgoto, destroços de casas, deixando pelo caminho a desolação de uma tragédia reiteradamente anunciada há 26 anos. Para Bohn, Silva e Bevian (2009, p. 165), esse fato é um clássico exemplo de conduta omissiva do poder público municipal, passível de indicar a aplicabilidade do "instituto da responsabilidade civil do Estado por conduta omissiva, mesmo diante de um fato de força maior, como foi o evento de novembro de 2008 ”.

Ao exposto, cumpre agregar que um dos principais elementos que desencadearam os desastres ambientais, tanto no exemplo anterior como na tragédia do Rio de Janeiro de 2010, está diretamente vinculado à atividade antrópica, ou seja, é o resultado do desmatamento de encostas e margens dos rios para a construção de assentamentos irregulares ou atividades agropecuárias (Bessa Junior, Doudstdar e Cortesi, 2011). Essa reflexão remete, de certo modo, ao dizer de Hans Jonas (2006, p. 278), que alerta no sentido de que na "maior parte das vezes, somente se faz um julgamento a posteriori, pois é necessário apostar para que a experiência nos mostre as suas consequências".

Mas o tema que mais ecoa hoje é que existem conhecimentos geotécnicos que, pelo tipo de rocha, declividades e drenagens existentes ou não, podem prever com precisão quase absoluta a ocorrência desses eventos ambientais - que de acidentes não têm praticamente nada, são totalmente previsíveis com base em dados técnicos. Nesse sentido, é muito constrangedor atribuir a eventos pluviométricos a ocorrência de fenômenos que pouco dependem apenas de chuva - ocorreriam em função de declividades, ausência de drenagem, localização imprópria e outros fatores, sendo as chuvas apenas elementos que detonam o processo, e não necessariamente o evento principal. Ainda, a causa principal tampouco é apenas a omissão ambiental do Estado. A causa principal é a histórica negligência com o planejamento sistêmico e a rígida implantação deste. Aqui também vale trazer à colação o pensamento de Giddens (2010, p. 126) sobre o excesso de predileção pelo planejamento de curto prazo, o que, para o autor, gera um desgaste do Estado, "aliado a uma falta de controles para lidar com o risco sistêmico”. Giddens (2010, p.126) complementa que não é tarefa fácil planejar no longo prazo, pois sempre ocorrerão "disputas entre os centros políticos, as regiões e as localidades”.

Aliás, lastimavelmente, grande parte dos Estados federados brasileiros vem sofrendo com esse tipo de problema: os poderes públicos municipais se mostram totalmente incompetentes para fiscalizar e controlar a distribuição demográfica em 
seus territórios, o que acaba por ocasionar uma série de transtornos e prejuízos a toda a população, havendo evidente nexo de causalidade com a conduta omissiva das administrações públicas.

Outro exemplo muito apropriado é a gestão de resíduos sólidos. Para empreendimentos e organizações de qualquer natureza são feitas - corretamente -, pelos órgãos ambientais, grandes e onerosas exigências, como valas para disposição de resíduos sólidos, com drenos testemunhos, selamento por polietileno de alta densidade - que efetivamente é o material mais adequado, em termos tecnológicos, no momento -, coberturas para que precipitações pluviométricas não ampliem o volume de chorume a ser produzido e tratado, entre outras.

Porém, o que se observa é que, para entes públicos municipais, existe uma tolerância tão grande que não se distingue mais entre o bom senso e a simples negligência. Todos nós sabemos das dificuldades orçamentárias dos municípios brasileiros, os quais, sem dúvida, encarnam o primo pobre da federação, formada pelos municípios mais Estados e União. Mas há de se definir limites de flexibilidade que resgatem o bom senso e não possam ser confundidos com simples negligência. Exemplo são programas cuja exequibilidade se dilua ao longo do tempo e, com isso, reduzam os investimentos, mas não a simples ignorabilidade que demanda a lembrança de negligência.

Os danos ambientais difusos gerados por depósitos de resíduos sólidos sem a devida proteção ambiental são muitas vezes intangíveis ou de difícil mensuração, por incluir fatores e dimensões difíceis até de avaliar em seu conjunto. A contaminação começa por lençóis freáticos, atinge cursos de água superficiais, aquíferos subterrâneos, solos, rochas, flora, fauna e as próprias atividades antrópicas, com uma intensidade que se diferencia pelo fardo de perturbações ou alterações sofridas pelo sistema natural ao longo dos anos e que são absolutamente difíceis de medir.

Logicamente, esse tipo de conduta omissiva também é observado nos mais diversos âmbitos do poder público, como na precariedade de conservação das rodovias federais de competência da União ou na rotineira falta de medicamentos gratuitos de uso excepcional geridos pelo Estado, por exemplo.

\section{CAsos Concretos de omissão Ambiental eSTATAl indenizÁvel NA JURISPRUDÊNCIA BRASILEIRA}

O Estado protege a natureza quando limita as subtrações excessivas e reduz as emissões nocivas, trabalhando simultaneamente para restaurar o ecossistema e para salvaguardar os interesses das presentes e das futuras gerações. Essa solidariedade de destino justifica uma diferença de intensidade da responsabilidade assumida (OST, 1997, p. 311-2). Observe-se: o Estado responde por omissão, como já verificado anteriormente, mas essa responsabilidade acresce quando se está diante de questões 
que envolvem a degradação do meio ambiente e ameaçam a existência dos seres vivos. Os tribunais brasileiros têm respondido satisfatoriamente e em seus posicionamentos argumenta que a administração pública responde por omissão quando não cumpre seu dever constitucional de fiscalizar empreendimentos que possam degradar o meio ambiente. Para prosseguir na elucidação, propõe-se discutir decisões que comprovem o compromisso pela responsabilização por omissão.

Em que pese a alguns julgados em sentido diverso (responsabilidade civil subjetiva), a jurisprudência vem evoluindo claramente na direção de enfrentar a questão pela responsabilidade civil por omissão estatal objetiva. É nesse contexto que deve ser lido o julgamento do STJ que fundamenta a decisão na responsabilidade civil do Estado por omissão no Recurso Especial no 604.725-PR (2003/0195400-5) (Brasil, 2005). Na sua origem, o Ministério Público Federal, motivado pela construção de uma via pública que tangencia o Rio Paraná, interpôs ação civil pública de responsabilidade por danos causados ao meio ambiente contra: a União Federal, o Estado do Paraná (recorrente), o município de Foz do Iguaçu e o Instituto Brasileiro do Meio Ambiente e dos Recursos Naturais Renováveis (Ibama). No pleito, solicita antecipação dos efeitos da tutela. O Estado do Paraná contestou o pedido, alegando ilegitimidade passiva. Em primeiro grau foi afastado o pleito de ilegitimidade passiva.

O relator do processo, ministro Castro Meira, chama a atenção para dois fatos que fundamentaram o recurso interposto pelo Ministério Público Federal:

a) da construção da via pública denominada Avenida Beira Rio, que tangencia o Rio Paraná por uma extensão de 7.620 m, compreendidos entre a Ponte Internacional da Amizade e a Avenida das Morenitas no Município de Foz do Iguaçu, e b) pelo não cumprimento por parte deste Município do Termo de Compromisso firmado com o IBAMA, para proteção do meio ambiente na área de preservação permanente em que se projetou a construção desta avenida, bem como restaurá-lo ao estado em que se encontrava antes da construção da citada obra (BRASIL, 2005, p. 5).

Na sequência, o Estado do Paraná interpôs agravo de instrumento, argumentando que sua participação na obra limitou-se ao financiamento desta e que as obras, objeto da controvérsia, foram iniciadas mediante licença do Ibama. O Estado do Paraná sustentou, ainda, que o ato que "gerou o suposto dano ambiental não decorreu de repasse da verba pública efetuada pelo recorrente, mas sim da má aplicação dessa verba pelo Município de Foz do Iguaçu” (BRASIL, 2005, p. 3).

Em resposta, o Superior Tribunal de Justiça, por unanimidade, acompanhou o voto do relator, ministro Castro Meira, em que este afirma que o Estado do Paraná tinha o dever de preservar e fiscalizar a obra em questão. Em sua justificativa, o relator assevera que o "Estado, no seu dever de fiscalização, deveria ter requerido o Estudo de Impacto Ambiental e seu respectivo relatório, bem como a realização de audiências 
públicas acerca do tema, ou até mesmo a paralisação da obra que causou o dano ambiental" (BRASIL, 2005, p.4). Fundamentou, ainda, que, em relação ao repasse das "verbas pelo Estado do Paraná ao Município de Foz de Iguaçu [ação], a ausência das cautelas fiscalizatórias no que se refere às licenças concedidas e as que deveriam ter sido confeccionadas pelo ente estatal” (BRASIL, 2005, p.4) refletem a omissão deste. Essa omissão concorreu para a produção do dano ambiental, e as circunstâncias postas, no olhar do relator Castro Meira, "são aptas a caracterizar o nexo de causalidade do evento, e assim, legitimar a responsabilização objetiva do recorrente” (BRASIL, 2005,p. 4).

Daí a assertiva do ministro Castro Meira ao dizer que: "independentemente da existência de culpa, o poluidor, ainda que indireto [Estado-recorrente] (art. $3^{\circ}$ da Lei $\mathrm{n}^{\circ} 6.938 / 81$ ), é obrigado a indenizar e reparar o dano causado ao meio ambiente [responsabilidade objetiva]". O ministro relator, ao proferir sua decisão, acompanhado dos demais ministros, fixou a legitimidade passiva do Estado do Paraná, fundamentando-a na seguinte expressão:

Preenchidos os requisitos para a configuração da responsabilidade civil [ação ou omissão, nexo de causalidade e dano], ressalta-se, também, que tal responsabilidade [objetiva] é solidária, o que legitima a inclusão das três esferas de poder no pólo passivo na demanda, conforme realizado pelo Ministério Público [litisconsórcio facultativo].

O caso em comento mostra que a tese aqui fundamentada é pela responsabilidade civil objetiva do Estado.

Outra análise parte do Recurso Especial n. 1071741/SP (2008/0146043-5 de 16/12/2010) (Brasil, 2010) - de relatoria do ministro Herman Benjamin -, interposto ao STJ pelo Ministério Público de São Paulo (MP/SP), que é bem ilustrativo. O MP/SP indica ser contrário ao artigo 535 do Código de Processo Civil e aos artigos $3^{\circ}$, IV, e $14, \S 1^{\circ}$, da Lei $n^{\circ} 6.939 / 81$ o argumento de que o Estado de São Paulo deve ser responsabilizado solidariamente pelo dano ambiental causado. Em suas alegações, considera que o fato de a administração embargar a obra não a isenta do ato de omissão, visto que a ela cabia adotar as medidas para evitar o desmatamento, a exploração predatória e a ocupação ilícita que resultaram na construção de uma residência dentro do Parque Estadual de Jacupiranga. A ação foi julgada procedente.

O ministro Herman Benjamin, em sua relatoria, destacou que "qualquer que seja a qualificação jurídica do degradador, público ou privado, no Direito brasileiro a responsabilidade civil pelo dano ambiental é de natureza objetiva, solidária e ilimitada” (BRASIL, 2010, p.2) e que a responsabilidade civil se rege pelos "princípios do poluidor-pagador, da reparação in integrum, da prioridade da reparação in natura e do favor debilis, esse último a legitimar uma série de técnicas de facilitação do acesso à Justiça, entre as quais se inclui a inversão do ônus da prova em favor da vítima ambiental”. 
Ao tratar da questão da responsabilidade civil do Estado por omissão, o ministro Herman Benjamin salienta que se trata de responsabilidade subjetiva ou por culpa (art. 37 da CF/88) e que ela enfrenta duas exceções principais, a saber: (i) "quando a responsabilização objetiva do ente público decorrer de expressa previsão legal, em microssistema especial, como na proteção do meio ambiente (Lei 6.938/1981, art. $3^{\circ}, \mathrm{IV}, \mathrm{c} / \mathrm{c}$ o art. $14, \S 1^{\circ}$ )" (BRASIL, 2010, p. 2); (ii) "quando as circunstâncias indicarem a presença de um standard ou dever de ação estatal mais rigoroso do que aquele que jorra, consoante a construção doutrinária e jurisprudencial, do texto constitucional” (BRASIL, 2010, p. 2, grifo do autor). Eis o problema: nos termos do $\S 1^{\circ}$ do artigo 70 da Lei $n^{\circ} 9.605 / 1998$, são titulares do dever/poder de implementação "os funcionários de órgãos ambientais integrantes do Sistema Nacional de Meio Ambiente - SISNAMA, designados para as atividades de fiscalização', além de outros a que se confira tal atribuição". Desse ponto de vista, a autoridade ambiental que tiver conhecimento da "infração ambiental é obrigada a promover a sua apuração imediata, mediante processo administrativo próprio, sob pena de co-responsabilidade" (BRASIL, 2010, p. 2, grifos do autor).

O relator observa que o dever/poder de fiscalização ambiental e urbanística do Estado não está limitado ao ato de embargar a obra ou a atividade irregular e denunciá-la. Seu dever/poder vai muito além, ou seja, não pode, por omissão, ignorar ou desprezar outras medidas, inclusive possessórias, que a lei põe à sua disposição e que poderiam evitar a "turbação ou o esbulho do patrimônio estatal e dos bens de uso comum do povo, resultante do desmatamento, construção, exploração ou presença humana ilícita” (BRASIL, 2010, p. 3). E complementa o relator: a administração é solidária, objetiva e ilimitadamente responsável, por força da Lei $\mathrm{n}^{\circ}$ 6.938/1981, "por danos urbanístico-ambientais decorrentes da omissão do seu dever de controlar e fiscalizar" (BRASIL, 2010, p.3), tendo o direito de impetrar, contra o agente público que foi relapso ou desidioso, medidas disciplinares, penais, civis e no campo da improbidade administrativa. A tese aqui fundamentada é pela responsabilidade subjetiva do Estado por omissão. Trata-se da resposta que surge como síntese da interpretação hermenêutica do dizer do ministro Herman Benjamin: "o dever-poder de controle e fiscalização ambiental [= dever/poder de implementação], além de inerente ao exercício do poder de polícia do Estado, provém diretamente do marco constitucional de garantia dos processos ecológicos essenciais" (BRASIL, 2010, p. 2, grifo do autor) e por isso deve ser respeitado e na sua omissão deve ser penalizado.

\section{CONSIDERAÇÕES FINAIS}

O avanço tecnológico, a industrialização crescente, o nascimento de uma sociedade de consumo de consumo sem limite, o crescimento populacional e o descompasso 
entre o dever e o poder estatal de preservar o meio ambiente para as presentes e as futuras gerações trazem como consequência riscos e perigos. Como se observou, a Constituição Federal deixa clara a responsabilidade do Estado que, por ação ou omissão, gerar danos irreversíveis ao meio ambiente.

$\mathrm{Na}$ análise jurisprudencial e doutrinária demonstrou-se que há uma discussão quanto ao modo como o Estado responde (objetivamente ou subjetivamente) frente ao dado ambiental causado por omissão. Assim, já é possível inferir que o STJ assume uma dimensão mais alargada do conceito de responsabilidade civil do Estado e, com base nisso, concluir que há uma tendência pela responsabilidade civil objetiva com base no risco. Isso permite que a responsabilidade objetiva supere a modalidade subjetiva e torna a primeira a regra geral. Assim, o Brasil, salvo algumas divergências doutrinárias, adota a responsabilidade civil objetiva do Estado pela teoria do risco administrativo (risco que a atividade pública gera para a sociedade, podendo acarretar danos para alguns, em benefício de outros).

O que sustenta esse dizer é o argumento de que a responsabilidade do Estado por omissão se apresenta alicerçada no ato ilícito e na aceitação do risco. Quando o Estado se omite, ele contribui significativamente para a ocorrência do dano ambiental. A culpa, nessa modalidade, é substituída pelo risco. Por outro lado, não se está a dizer que a sociedade deve ser duplamente penalizada; os tribunais devem ser sensíveis ao fato de o cidadão - em danos causados por causas naturais com difícil identificação do elemento culpa na omissão - ser penalizado tanto pelo dano ambiental sofrido como pelo valor pecuniário que o Estado (contribuições do cidadão) deverá aportar.

O raciocínio de Hans Jonas tem uma vantagem decisiva sobre esses argumentos. Para o autor, embora não exista uma receita para governar, o marco temporal é a responsabilidade, que ganhou uma dimensão totalmente nova com a consciência do risco e do dano ambiental. A responsabilidade por omissão estatal se tornará parte das preocupações das administrações em não lesar duplamente o cidadão. O Estado Socioambiental de Direito, fruto da luta ambiental em favor do equilíbrio ambiental e da sadia qualidade de vida, certamente será um dos principais pontos dos programas de governo.

As urgências ambientais do momento terão prioridade, e a questão transformouse de tal maneira que os tribunais já estão decidindo pela responsabilidade objetiva por omissão no campo da responsabilidade ambiental. E isso, buscando novamente apoio em Hans Jonas, possibilita um conteúdo inteiramente novo e um alcance sobre o futuro na perspectiva da responsabilidade intergeracional, tanto na esfera do fazer político como na esfera da moral política. 


\section{REFERÊNCIAS BIBLIOGRÁFICAS}

ALEXANDRINO, Marcelo; PAUlO, Vicente. Direito administrativo. 5. ed. Rio de Janeiro: Impetus, 2004. BARACHO JÚNIOR, José Alfredo de Oliveira. Responsabilidade civil por dano ao meio ambiente. Belo Horizonte: Del Rey, 2000.

BECK, Ulrich. La sociedad del riesgo mundial: en busca de la seguridad perdida. Traduzido por Rosa S. Carbó. Barcelona: Paidós, 2008.

BESSA JUNIOR, Oduvaldo; DOUSTDAR, Neda Mohtadi; CORTESI, Luiz Antonio. Vulnerabilidade de municípios do Paraná aos riscos de desastres naturais. Caderno IPARDES, Curitiba, v. 1. n. 1, p. 82-100, 2011. Disponível em: <http://www.ipardes.pr.gov.br/ojs/index.php/cadernoipardes/article/view/80>. Acesso em: 3 jan. 2012.

BOHN, Noemia; SILVA, Vanilda da; BEVIAN, Elsa Cristina. A responsabilidade civil do Estado por omissão frente ao desastre. In: FRANK, Beate; SEVEGNANI, Lucia (Orgs.). Desastre de 2008 no Vale do Itajaí: água, gente e política. Blumenau: Agência de Água do Vale do Itajaí, 2009. p. 158-165.

BRASIL. Superior Tribunal de Justiça. Recurso Especial n. 604.725 - PR (2003/0195400-5 de 22/05/2005). Relator ministro Castro Meira. Disponível em: <https://ww2.stj.jus.br/revistaeletronica/ita.asp>. Acesso em: 16 abr. 2011

Superior Tribunal de Justiça. Recurso Especial n. 1071741- SP (2008/0146043-5 de 16/12/2010).

Relator ministro Herman Benjamin. Disponível em:

<https://ww2.stj.jus.br/revistaeletronica/ita.asp?registro=200801460435\&dt_publicacao=16/12/2010>. Acesso em: 18 abr. 2011.

CAHALI, Yussef Said. Responsabilidade civil do Estado. 2. ed. São Paulo: Malheiros, 1995.

CARVALHO, Délton Winter de. Dano ambiental futuro: a responsabilização civil pelo risco ambiental. Rio de Janeiro: Forense Universitária, 2008.

CAVALIERI FILHO, Sergio. Programa de responsabilidade civil. 7. ed. São Paulo: Atlas, 2007.

FREITAS, Juarez. Responsabilidade do Estado e o princípio da proporcionalidade: vedação de excessos e omissões. Revista Latino-Americana de Estudos Constitucionais, São Paulo, n. 6, p. 145-168, jul./dez. 2005. GIDDENS, Anthony. A política da mudança climática. Traduzido por Vera Ribeiro. Rio de Janeiro: Zahar, 2010. JONAS, Hans. O princípio responsabilidade: ensaio de uma ética para a civilização tecnológica. Traduzido por Marijane Lisboa e Luiz Barros Montez. Rio de Janeiro: Contraponto; Ed. PUC-Rio, 2006

JUCOVSKY, Vera Lúcia R. S. Responsabilidade do Estado por danos ambientais: Brasil - Portugal. São Paulo: Juarez de Oliveira, 2000.

LEITE, José Rubens Morato; PILATI, Luciana Cardoso. Responsabilidade de dano ambiental no sistema da responsabilização civil: 25 anos da Lei 6.938/81. Revista Sequência, Santa Catarina, v. 27, n. 53, p. 43-80, dez. 2006

MELLO, Celso Antônio Bandeira de. Elementos de direito administrativo. 3. ed. São Paulo: Malheiros, 1992. MELLO, Celso Antônio Bandeira de: Responsabilidade extracontratual do Estado por comportamentos administrativos. Revista dos Tribunais, São Paulo, n. 552, p. 11-20, out. 1981.

METZGER, Paquale. Medio ambiente urbano y riesgos: elementos de reflexión. In: FERNANDES, M. A. (Comp.). Ciudades en riesgo: degradación ambiental, riesgos urbanos y desastres en América Latina. La Red, 1996. Disponível em: <http://www.lared.org.pe/publicaciones/libros/4194/8cap3.htm>. Acesso em: 3 jan. 2012.

MILARÉ, Édis. Direito do ambiente. 5. ed. São Paulo: Editora Revista dos Tribunais, 2009.

MIRRA, Álvaro Luiz Valery. A noção de poluidor-pagador na Lei nº 6.938/91 e a questão da responsabilidade solidária do Estado pelos danos ambientais causados por particulares. In: LEITE, José Rubens Morato; DANTAS, Marcelo Buzaglo. Aspectos processuais do direito ambiental. 3. ed. Rio de Janeiro: Forense Universitária, 2010, p. 1-17.

OST, François. A natureza à margem da lei: a ecologia à prova do direito. Traduzido por Joana Chaves. Lisboa: Instituto Piaget, 1997.

ROHDE, Geraldo Mario. Estudos de Impacto Ambiental: a situação brasileira. In: VERDUN, Roberto; MEDEIROS, Rosa Maria (Orgs.). RIMA Relatório de Impacto Ambiental: legislação, elaboração e resultados. Porto Alegre: Universidade Federal do Rio Grande do Sul, 1990.

SARLET, Ingo Wolfgang; FENSTERSEIFER, Tiago. Direito constitucional ambiental: estudos sobre a Constituição, os direitos fundamentais e a proteção do ambiente. São Paulo: Editora Revista dos Tribunais, 2011. VITTA, Heraldo Garcia. Responsabilidade civil e administrativa por dano ambiental. São Paulo: Malheiros, 2008. 


\author{
Universidade Feevale \\ Pró-Reitoria de Pesquisa e Inovação \\ RS 239, n. 2755 \\ 93352-000 \\ Novo Hamburgo - RS - Brasil \\ haidelafeevale.br
}

Universidade Feevale Pró-Reitoria de Pesquisa e Inovação RS 239, n. 2755 93352-000 Novo Hamburgo - RS - Brasil rnaimedafeevale.br

Rua Nossa Senhora da Conceição, n. 333, conj. 21 Centro - 93220-270 Sapucaia do Sul - RS - Brasil gonzagaadolfolayahoo.com.br

Avenida Liberdade, n. 1166 Santa Isabel - 94480-500 Viamão - RS - Brasil ioselucianelayahoo.com.br

\section{Haide Maria Hupffer}

DOUTORA EM DIREITO (UNISINOS) Docente do Programa de Pós-Graduação EM Qualidade AmBIENTAL

Líder do Grupo de Pesquisa DiReito e Desenvolvimento E Linha de Pesquisa DiReito Ambiental E Desenvolvimento DA UNIVERSIDADE FEEVALE

\section{Roberto Naime}

DOUTOR EM GEOLOGIA AMBIENTAL (UFPR) Docente do Programa de Pós-Graduação em Qualidade AmBIENTAL DA UnIVERSIDADE FEEVALE

\section{Luiz Gonzaga Silva Adolfo}

DOUTOR EM DIREITO (UNISINOS) Professor do Programa de Pós-Graduação (Mestrado e Doutorado) da UNISC Professor nos Cursos de graduação EM DiReITo DA ULBRA E DA UNISC

Advogado

\section{Iose Luciane Machado Corrêa}

AdVogada | 